\title{
Identification of FGFR3-TACC3 gene fusion in metastatic gastric cancer
}

\section{Youjin Kim${ }^{1}$, Seung Tae Kim¹, Jeeyun Lee ${ }^{1}$, Won Ki Kang ${ }^{1}$, Kyoung-Mee Kim², Se Hoon Park ${ }^{1}$}

${ }^{1}$ Division of Hematology-Oncology, Department of Medicine, Samsung Medical Center, Sungkyunkwan University School of Medicine, Seoul, Korea

${ }^{2}$ Department of Pathology and Translational Genomics, Samsung Medical Center, Sungkyunkwan University School of Medicine, Seoul, Korea

Received: August 25, 2017

Revised: December 11, 2017

Accepted: December 11, 2017

Corresponding author:

Se Hoon Park

Division of Hematology-

Oncology, Department of

Medicine, Samsung Medical

Center, Sungkyunkwan

University School of Medicine,

81 Irwon-ro, Gangnam-gu,

Seoul 06351, Korea

Tel: +82-2-3410-1767

E-mail:sh1767.park@samsung.com

This is an Open Access article distributed under the terms of the Creative Commons Attribution Non-Commercial License (http:// creativecommons.org/licenses/ by-nc/4.0/).

\section{ABSTRACT}

In preclinical cancer models, fibroblast growth factor receptor (FGFR) gene aberration has been known to be associated with increased tumor cell proliferation and survival in several cancer types. Oncogenic fusions consisting of FGFR3 and transforming acid coiled coil 3 (TACC3) had been identified as potential therapeutic target. We report on a gastric cancer patient with liver metastases who harbored FGFR3-TACC3 fusion which is extremely rare in gastrointestinal cancer. Herein, we report a case presentation with literature review of FGFR3-TACC3 fusion.

Keywords: FGFR3-TACC3; Metastatic gastric cancer

\section{INTRODUCTION}

Gastric cancer (GC) is the second most common cause of cancer-related deaths worldwide, and the prognosis of advanced gastric cancer is still poor [1,2]. The fibroblast growth factor/fibroblast growth factor receptor (FGF/FGFR) system consists of 18 ligands (FGFs) and four receptors (FGFR1-4) [3,4]. Upon ligand binding FGFRs activate several signaling cascades, particularly phosphoinositide 3-kinase (PI3K)/protein kinase B (AKT) and mitogen-activated protein kinases (MAPK)/extracellular-signal-regulated kinase (ERK) [5]. In turn, this leads to regulation of diverse cellular functions which play a pivotal role not only in physiological homeostasis but also in carcinogenesis, e.g. proliferation, motility, angiogenesis, anti-apoptosis and drug resistance $[3,6]$. More recently, FGFR fusion proteins have been increasingly detected in various human cancers, and transforming acid coiled coil 3 (TACC3) gene has been identified as an important partner of these FGFR fusions and was known to force dimerization and consequently activation of FGFR3 kinase activity in several solid tumors [7,8]. The contribution of such fusions to cancers of the upper digestive tract has remained largely unknown, but was detected in esophageal squamous cell carcinoma, recently $[9,10]$. Here we report a case of metastatic GC harboring an activating FGFR3-TACC3 mutation for the first time. 


\section{CASE REPORT}

In August 2010, a 52-year-old man was referred to our hospital for treatment of gastric cancer which was identified during annual endoscopic examination as part of national cancer screening program in Korea. The initial computed tomography (CT) scan at diagnosis demonstrated wall thickening in the lesser curvature of the lower body without any evidence for distant metastasis. He received curative subtotal gastrectomy, Billroth I anastomosis, D2 dissection and the
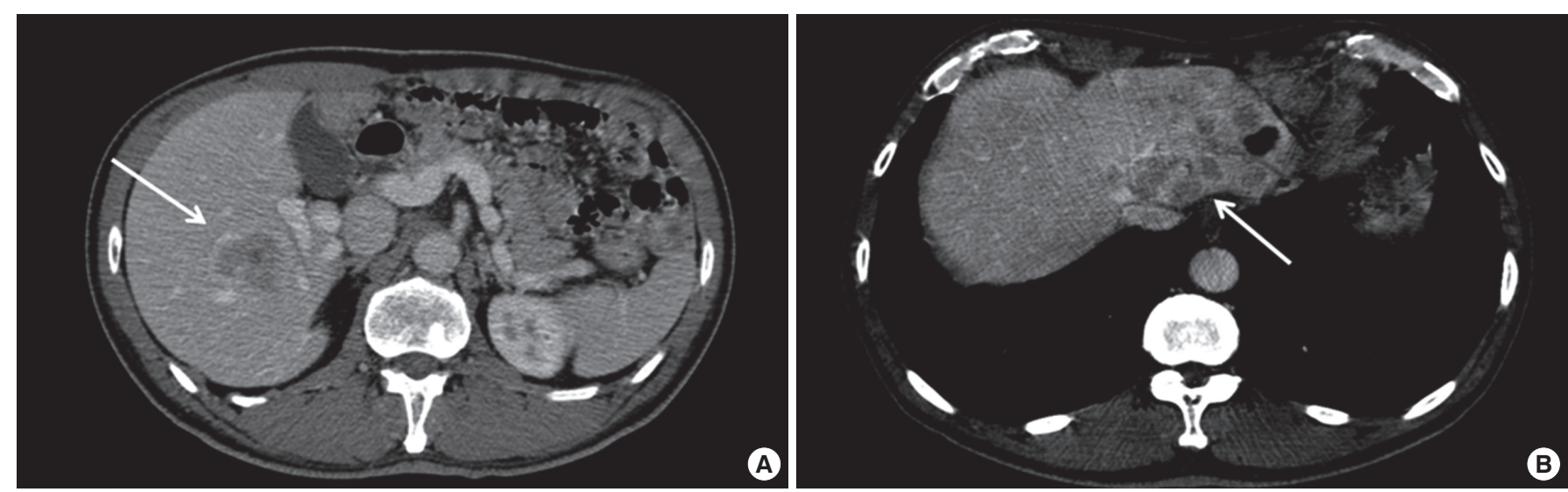

Fig. 1. Computed tomography of the abdomen after 15 months since surgery. It showed multiple hepatic metastases, medium-sized and small nodules in the (A) right (arrow) and (B) left (arrow) hepatic lobes.

Table 1. Cross-sectional studies and case series reporting positive FGFR-TACC3 fusions

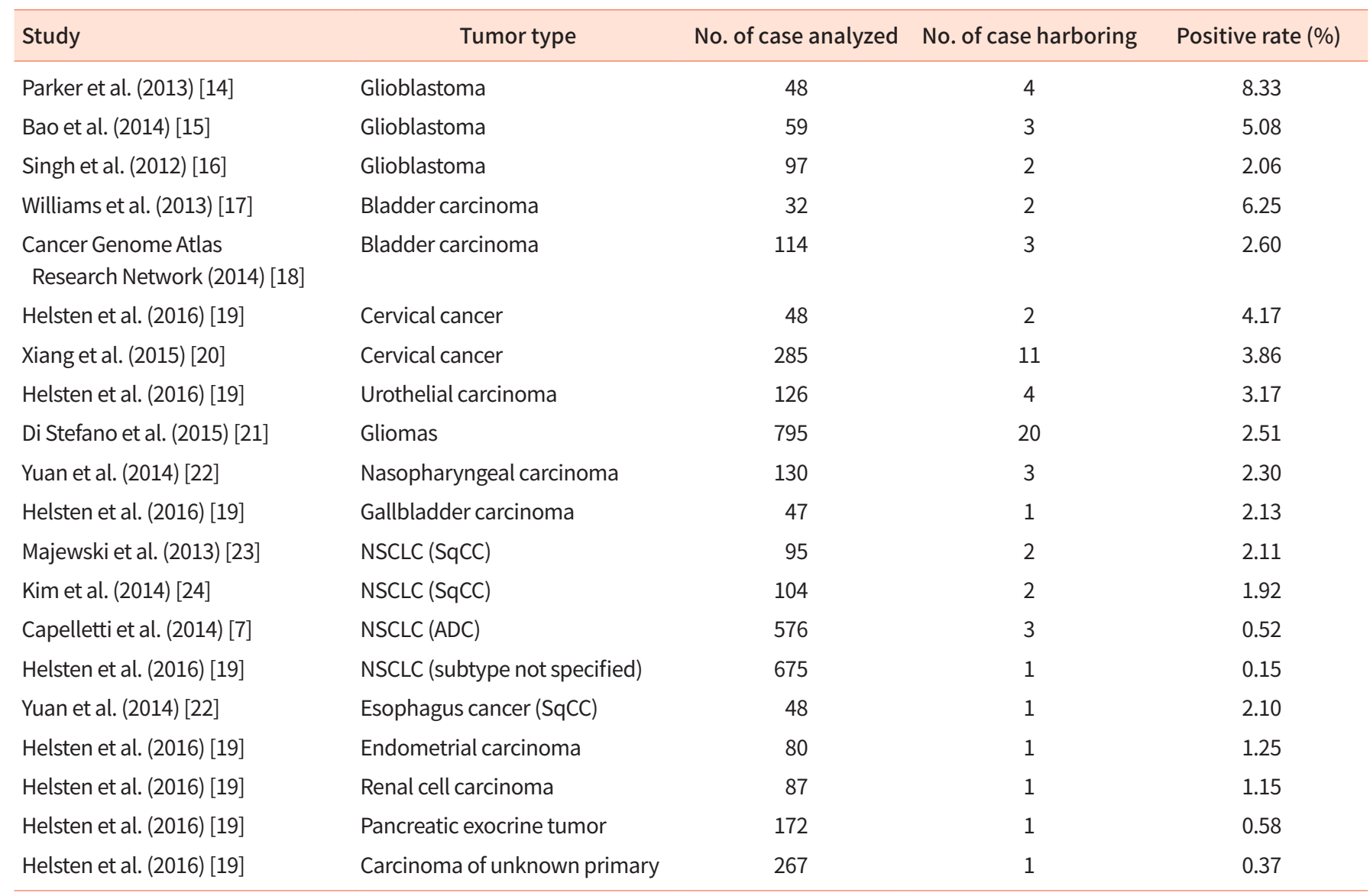

FGFR-TACC3, fibroblast growth factor receptors-transforming acid coiled coil 3; NSCLC, non-small cell lung cancer; SqCC, squamaous cell carcinoma; ADC, adenocarcinoma. 


\section{PRECISION AND FUTURE MIEDICINE \\ FGFR3-TACC3 fusions in gastric cancer}

pathologic examination revealed a moderately-differentiated adenocarcinoma, PT3NOM0, stage IIA (erbb2 negative). As postoperative adjuvant treatment, the patient completed 8 cycles of TS-1 chemotherapy given the pathologic stage. During scheduled surveillance for recurrence, the patient developed multiple liver metastases after 15 months postsurgery (Fig. 1). Liver biopsy was performed and the pathology revealed metastasized gastric adenocarcinoma. He received first-line capecitabine/oxaliplatin (oxaliplatin $130 \mathrm{mg} / \mathrm{m}^{2}+$ capecitabine $1,000 \mathrm{mg} / \mathrm{m}^{2}$ by mouth twice a day, day 1 to 14) every 21 days, and achieved partial response for 5 months. Follow-up CT scan still showed $1.1 \mathrm{~cm}$ metastatic lesion in $\mathrm{S6}$ which was further ablated by CT-guided percutaneous radiofrequency ablation (RFA). The patient received ramu- cirumab/paclitaxel with complete remission after RFA until he developed another liver metastases. We identified FGFR3-TACC3 fusion in his tumor using next-generation sequencing (NGS) platform that we routinely use in the clinic (Oncomine ${ }^{\mathrm{TM}}$ Comprehensive Assay v3, www.thermofisher. com).

\section{DISCUSSION}

Recent advances in sequencing technologies have led to an increase in the discovery of novel and therapeutically actionable genomic alterations in a broad range of cancers. Comprehensive clinical sequencing programs for cancer patients have been initiated at a variety of medical centers including

Table 2. Summary of FGFR inhibitors currently investigated in clinical trials

\begin{tabular}{|c|c|c|c|c|}
\hline Inhibitor (manufacturers) & Cancer type & $\begin{array}{l}\text { Identification of } \\
\text { Clinicaltrials. gov }\end{array}$ & Phase & $\begin{array}{l}\text { Estimated } \\
\text { enrollment }(n)\end{array}$ \\
\hline \multirow[t]{2}{*}{ Dovitinib (Novartis) } & FGFR3-mutated or -overexpressed urothelial cancer & NCT01732107 & II & 50 \\
\hline & Metastatic renal cell cancer (Dovitinib versus sorafenib) & NCT01223027 & III & 564 \\
\hline $\begin{array}{l}\text { Ponatinib } \\
\text { (ARIAD Pharmaceuticals) }\end{array}$ & FGFR genetically aberrant advanced-stage cancers & NCT02272998 & II & 45 \\
\hline Lucitanib (Clovis Oncology) & Any FGF-related aberration in advanced or metastatic lung cancer & NCT02109016 & II & 18 \\
\hline \multirow[t]{2}{*}{ AZD4547 (AstraZeneca) } & FGFR genetically aberrant NSCLC & NCT02664935 & II & 620 \\
\hline & FGFR genetically aberrant NSCLC & NCT02117167 & II & 650 \\
\hline \multirow[t]{6}{*}{ NVP-BGJ398 (Novartis) } & $\begin{array}{l}\text { FGFR1-3 genetically aberrant solid tumors, FGFR1-amplified } \\
\text { squamous cell lung cancer, FGFR3-mutated or fused bladder cancer }\end{array}$ & NCT01004224 & I & 208 \\
\hline & $\begin{array}{l}\text { FGFR genetically aberrant advanced solid tumors in an Asian } \\
\text { population }\end{array}$ & NCT01697605 & I & 22 \\
\hline & $\begin{array}{l}\text { FGFR genetically aberrant advanced solid tumors with PIK3CA } \\
\text { mutations }\end{array}$ & NCT01928459 & I & 62 \\
\hline & $\begin{array}{l}\text { Glioma subtypes with FGFR1-TACC1 fusion, FGFR3-TACC3 fusion, } \\
\text { activating mutation in FGFR1-3 }\end{array}$ & NCT01975701 & II & 24 \\
\hline & FGFR genetically aberrant solid or hematological cancers & NCT02160041 & II & 90 \\
\hline & FGFR genetically aberrant advanced or metastatic cholangiocarcinoma & NCT02150967 & II & 120 \\
\hline \multirow[t]{2}{*}{ JNJ-42756493 (Janssen) } & FGFR genetically aberrant advanced urothelial cancer & NCT02365597 & II & 210 \\
\hline & $\begin{array}{l}\text { Asian participants with NSCLC, gastric cancer, urothelial cancer, } \\
\text { esophageal cancer, cholangiocarcinoma }\end{array}$ & NCT02699606 & II & 75 \\
\hline LY2874455 (Lilly) & Advanced-stage cancer & NCT01212107 & I & 94 \\
\hline TAS120 (Taiho Oncology) & FGFR genetically aberrant advanced solid tumors or multiple myeloma & NCT02052778 & I & 835 \\
\hline $\begin{array}{l}\text { Debio-1347 } \\
\text { (Debiopharm International) }\end{array}$ & FGFR1-3 genetically aberrant solid tumors I & NCT01948297 & I & 112 \\
\hline \multirow[t]{2}{*}{ FP-1039 (GlaxoSmithKline) } & $\begin{array}{l}\text { FGFR genetically aberrant solid malignancies in combination with } \\
\text { paclitaxel and carboplatin or docetaxel }\end{array}$ & NCT01868022 & I & 120 \\
\hline & Advanced solid tumors I & NCT01363024 & I & 24 \\
\hline
\end{tabular}

FGFR-TACC3, fibroblast growth factor receptors-transforming acid coiled coil 3; NSCLC, non-small cell lung cancer; PIK3CA, phosphoinositide-3-kinase, catalytic, alpha polypeptide. 
our center [11]. Recently, FGFR3-TACC3 gene fusion has been identified in several cancers including glioblastoma, lung cancer, bladder cancer, oral cancer, head and neck squamous cell carcinoma, gallbladder cancer, and cervical cancer. We summarized the incidence of FGFR3-TACC3 rearrangements in various tumor types in Table 1 that had been reported in the literature [7,12-24]. To the best of our knowledge, FGFR3-TACC3 fusions have not previously been described in GC.

FGFR3-TACC3 fusion proteins appear to localize to spindle poles and cause disruption of chromosome segregation and aneuploidy by a mechanism dependent on FGFR tyrosine kinase activity [25]. The tumor-initiating activity of the FGFR3TACC3 fusion protein suggests that it has growth-promoting signaling functions that complement the loss of mitotic fidelity and aneuploidy to induce full-blown tumorigenesis. The clinical relevance of FGFR3-TACC3 has been underscored by preliminary results from clinical studies and case reports of tumor responses to the treatment with FGFR inhibitors. For instance, the phase I trial with FGFR inhibitor JNJ-42756493 including 65 patients with advanced solid tumors included 4 patients with FGFR3-TACC3 translocation [26]. We outlined the evidence from early phase clinical trials support that FGFR aberrations can represent targetable events and several clinical trials of FGFR inhibitors, including with BGJ398 (NCT01928459, NCT 01975701, NCT01697605, and NCT01004224), are currently under clinical development in Table 2 [13].

This report is the first to identify FGFR3-TACC3 fusion proteins in gastric cancer, and it provides proof of concept that treating with an FGFR inhibitor can result in clinical benefit in metastatic GC carrying FGFR3-TACC3 translocation in agreement with results observed in other malignancies. In addition, our findings suggest the importance of a comprehensive genomic profiling approach able to detect all classes of genomic alterations including uncommon gene fusions to reveal potentially targetable somatic alterations.

\section{CONFLICTS OF INTEREST}

No potential conflict of interest relevant to this article was reported.

\section{REFERENCES}

1. Jemal A, Bray F, Center MM, Ferlay J, Ward E, Forman D. Global cancer statistics. CA Cancer J Clin 2011;61:69-90.

2. Lee J, Kim KM. Biomarkers for gastric cancer: molecular classification revisited. Precis Future Med 2017;1:59-68.
3. Dieci MV, Arnedos M, Andre F, Soria JC. Fibroblast growth factor receptor inhibitors as a cancer treatment: from a biologic rationale to medical perspectives. Cancer Discov 2013;3:264-79.

4. Brooks AN, Kilgour E, Smith PD. Molecular pathways: fibroblast growth factor signaling: a new therapeutic opportunity in cancer. Clin Cancer Res 2012;18:1855-62.

5. Turner N, Grose R. Fibroblast growth factor signalling: from development to cancer. Nat Rev Cancer 2010;10: 116-29.

6. Katoh M, Nakagama H. FGF receptors: cancer biology and therapeutics. Med Res Rev 2014;34:280-300.

7. Capelletti M, Dodge ME, Ercan D, Hammerman PS, Park $\mathrm{SI}$, Kim J, et al. Identification of recurrent FGFR3-TACC3 fusion oncogenes from lung adenocarcinoma. Clin Cancer Res 2014;20:6551-8.

8. Hood FE, Royle SJ. Pulling it together: the mitotic function of TACC3. Bioarchitecture 2011;1:105-9.

9. Mizukami T, Sakai K, Naruki S, Taniyama T, Horie Y, Izawa $\mathrm{N}$, et al. Identification of a FGFR3-TACC3 fusion in esophageal cancer. Ann Oncol 2017;28:437-8.

10. Huang ZL, Lin ZR, Xiao YR, Cao X, Zhu LC, Zeng MS, et al. High expression of TACC3 in esophageal squamous cell carcinoma correlates with poor prognosis. Oncotarget 2015;6:6850-61.

11. Roychowdhury S, lyer MK, Robinson DR, Lonigro RJ, Wu YM, Cao X, et al. Personalized oncology through integrative high-throughput sequencing: a pilot study. Sci Transl Med 2011;3:111ra21.

12. Babina IS, Turner NC. Advances and challenges in targeting FGFR signalling in cancer. Nat Rev Cancer 2017;17: 318-32.

13. Costa R, Carneiro BA, Taxter T, Tavora FA, Kalyan A, Pai SA, et al. FGFR3-TACC3 fusion in solid tumors: mini review. Oncotarget 2016;7:55924-38.

14. Parker BC, Annala MJ, Cogdell DE, Granberg KJ, Sun Y, Ji P, et al. The tumorigenic FGFR3-TACC3 gene fusion escapes miR-99a regulation in glioblastoma. J Clin Invest 2013; 123:855-65.

15. Bao ZS, Chen HM, Yang MY, Zhang CB, Yu K, Ye WL, et al. RNA-seq of 272 gliomas revealed a novel, recurrent PTPRZ1-MET fusion transcript in secondary glioblastomas. Genome Res 2014;24:1765-73.

16. Singh D, Chan JM, Zoppoli P, Niola F, Sullivan R, Castano A, et al. Transforming fusions of FGFR and TACC genes in human glioblastoma. Science 2012;337:1231-5.

17. Williams SV, Hurst CD, Knowles MA. Oncogenic FGFR3 
gene fusions in bladder cancer. Hum Mol Genet 2013;22: 795-803.

18. Cancer Genome Atlas Research Network. Comprehensive molecular characterization of urothelial bladder carcinoma. Nature 2014;507:315-22.

19. Helsten T, Elkin S, Arthur E, Tomson BN, Carter J, Kurzrock $R$. The FGFR landscape in cancer: analysis of 4,853 tumors by next-generation sequencing. Clin Cancer Res 2016;22:259-67.

20. Xiang L, Li J, Jiang W, Shen X, Yang W, Wu X, et al. Comprehensive analysis of targetable oncogenic mutations in chinese cervical cancers. Oncotarget 2015;6:4968-75.

21. Di Stefano AL, Fucci A, Frattini V, Labussiere M, Mokhtari K, Zoppoli $\mathrm{P}$, et al. Detection, characterization, and inhibition of FGFR-TACC fusions in IDH wild-type glioma. Clin Cancer Res 2015;21:3307-17.

22. Yuan L, Liu ZH, Lin ZR, Xu LH, Zhong Q, Zeng MS. Recurrent FGFR3-TACC3 fusion gene in nasopharyngeal carci- noma. Cancer Biol Ther 2014;15:1613-21.

23. Majewski IJ, Mittempergher L, Davidson NM, Bosma A, Willems SM, Horlings HM, et al. Identification of recurrent FGFR3 fusion genes in lung cancer through kinome-centred RNA sequencing. J Pathol 2013;230:270-6.

24. Kim Y, Hammerman PS, Kim J, Yoon JA, Lee Y, Sun JM, et al. Integrative and comparative genomic analysis of lung squamous cell carcinomas in East Asian patients. J Clin Oncol 2014;32:121-8.

25. Yao R, Natsume Y, Saiki Y, Shioya H, Takeuchi K, Yamori T, et al. Disruption of Tacc3 function leads to in vivo tumor regression. Oncogene 2012;31:135-48.

26. Tabernero J, Bahleda R, Dienstmann R, Infante JR, Mita A, Italiano A, et al. Phase I dose-escalation study of JNJ42756493, an oral pan-fibroblast growth factor receptor inhibitor, in patients with advanced solid tumors. J Clin Oncol 2015;33:3401-8. 